\title{
Insect immunity: oral exposure to a bacterial pathogen elicits free radical response and protects from a recurring infection
}

\author{
Lauri Mikonranta $^{1 *}$, Johanna Mappes ${ }^{1}$, Minna Kaukoniitty ${ }^{1}$ and Dalial Freitak ${ }^{1,2}$
}

\begin{abstract}
Background: Previous exposure to a pathogen can help organisms cope with recurring infection. This is widely recognised in vertebrates, but increasing occasions are also being reported in invertebrates where this phenomenon is referred to as immune priming. However, the mechanisms that allow acquired pathogen resistance in insects remain largely unknown.

Results: We studied the priming of bacterial resistance in the larvae of the tiger moth, Parasemia plantaginis using two gram-negative bacteria, a pathogenic Serratia marcescens and a non-pathogenic control, Escherichia coli. A sublethal oral dose of $S$. marcescens provided the larvae with effective protection against an otherwise lethal septic infection with the same pathogen five days later. At the same time, we assessed three anti-bacterial defence mechanisms from the larvae that had been primarily exposed to the bacteria via contaminated host plant. Results showed that S. marcescens had induced a higher amount of reactive oxygen species (ROS) in the larval haemolymph, possibly protecting the host from the recurring infection.

Conclusions: Our study supports the growing evidence of immune priming in insects. It shows that activation of the protective mechanism requires a specific induction, rather than a sheer exposure to any gram-negative bacteria. The findings indicate that systemic pathogen recognition happens via the gut, and suggest that persistent loitering of immune elicitors or anti-microbial molecules are a possible mechanism for the observed prophylaxis. The self-harming effects of ROS molecules are well known, which indicates a potential cost of increased resistance. Together these findings could have important implications on the ecological and epidemiological processes affecting insect and pathogen populations.
\end{abstract}

Keywords: Bacterial resistance, Gram-negative, Immune priming, Immunological loitering, Insect immunity, Reactive oxygen species, Parasemia plantaginis, Serratia marcescens

\section{Introduction}

Recurring infections are common in the natural environment. Antibody based immunological memory has evolved in jawed vertebrates to cope with the threat of multiple infections. Invertebrates, being relatively short lived, lack antibodies [1]. However, evidence of insects being protected from pathogens they have previously encountered, has accumulated during the past decade e.g. [2-6]. The phenomenon has been coined as immune priming,

\footnotetext{
* Correspondence: lauri.mikonranta@jyu.fi

${ }^{1}$ Centre of Excellence in Biological Interactions, Department of Biological and Environmental Science, University of Jyväskylä, P.O. Box 35, Jyväskylä Fl-40014, Finland

Full list of author information is available at the end of the article
}

and advances in insect immunity have shown that the innate and adaptive systems might be functionally closer to each other than previously thought $[7,8]$.

Development, upregulation, and long-term maintenance of the innate immunity come with fitness costs that can be seen in various life-history traits [2,9-12]. A balance between the costs and the benefits of defences must give a selective advantage to individuals that have the optimal level of protection against the pathogens they are likely to encounter $[3,13,14]$. The protection could be achieved by a mechanism that allows enhanced reactivation of certain immune defences if the host faces a recurring infection, akin to vertebrate immune memory [4]. Alternatively, it might be beneficial to simply stay prepared for a recurring 
immune insult after the first encounter with immune elicitors or anti-microbial molecules that can remain stably expressed in the haemolymph [1-3]. The first encounter would serve as a cue for a threat of infection and upregulate the appropriate repertoire of defensive molecules $[2,3,13]$. This kind of 'immunological loitering' [3,15] might be considered as just a coincidental side effect of the primary pathogen detection, but we argue that there are reasons to assume that it is an adaptive trait. If non-infective pathogens can be detected before they become infective, the beneficial effect would be similar to density dependent prophylaxis, [16] where higher density of conspecifics indicates a higher risk of parasite encounter. There is ample evidence that many insects can maintain high levels of various immune molecules in their haemolymph for up to 44 days after immune induction [17-24]. Thus, taking the costs into account, it is hard to believe that this kind of prolonged immune reaction could have evolved without fitness benefits [2].

The anti-microbial mechanisms that insects use immediately when infections occur are relatively well known [25]. The detection of invading bacteria by gram-negative binding protein and peptidoglycan recognition protein leads to the activation of Imd and Toll signalling pathways that induce humoral and cellular responses, providing insects with coarse immunological specificity. These pathways can induce the release of bactericidal reactive oxygen species (ROS), different anti-microbial peptides and specialised haemocytes that also control melanisation and phenoloxidase (PO) activity [7,25-28]. At the same time, both $\mathrm{PO}$ and ROS related responses are considered to have high costs as they are accompanied with autoimmune effects $[29,30]$. Although some good explanations, like phagocytosis, controlled by the Toll pathway $[7,31,32]$ have been proposed, the mechanisms behind priming against an infection occurring later in life, or even in subsequent generations, remain largely unknown $[4,31,33]$.

In this paper we report how midgut mediated immune priming occurs in wood tiger moth Parasemia plantaginis (Linnaeus 1758) larvae against an environmental opportunistic bacterial pathogen. We primed the larvae, by exposing them orally to a non-infective dose of pathogenic Serratia marcescens and to a similarly gram-negative but nonpathogenic control bacterium Escherichia coli. We then assessed the consequences of primary oral encounter with the bacteria in two ways: first, indirectly by measuring the level of immunocompetence (PO, lytic, and ROS activity) from the larval haemolymph five days after the initial oral exposure, and then directly by measuring the survival after a severe secondary septic infection. A sublethal oral dose of $S$. marcescens provided the larvae with resistance against an otherwise lethal septic infection but the nonpathogenic control bacterium failed to confer protection. Priming with $S$. marcescens also induced a higher amount of ROS in the larval haemolymph, an antimicrobial defence that persisted until the secondary infection. This finding offers a potential, novel mechanistic explanation for acquired resistance in insects. Additionally, the activation of the protective mechanism seems to require more specific induction than a sheer exposure to any gram-negative bacteria, suggesting systemic pathogen recognition via midgut.

\section{Results}

Larval survival was significantly affected by the interaction between priming ( $1^{\text {st }}$ exposure) and injection ( $2^{\text {nd }}$ exposure) treatments (priming, $\mathrm{df}=1 \mathrm{Wald}=1.1, \mathrm{p}=0.290$; injection, $\mathrm{df}=1$, Wald $=64.3, \mathrm{p}<0.001$; priming $\times$ injection, $\mathrm{df}=1$, Wald $=15.1, \mathrm{p}<0.001)$. This indicated that larvae survived the injection differently depending on the previous oral priming. The four priming-injection groups $(\mathrm{df}=3)$ were further compared using pairwise Kaplan-Meier log-rank statistics (Table 1). Larvae injected with the control bacterium showed very low mortality and did not differ from each other regardless of the priming (Serratia-control: $13.8 \%$ mortality and control-control: 9.1\% mortality). Larvae injected with the pathogenic S. marcescens experienced only moderate mortality if they had been previously primed with it (Serratia-Serratia: $37.4 \%)$, but very high mortality if primed with the control (control-Serratia: 90.4\%) (Figure 1). There was altogether less than $5 \%$ background mortality among the larvae during the priming and no difference between the groups (data not shown).

Larvae that were primarily exposed to $S$. marcescens had $4.8 \%$ higher ROS concentration in their haemolymph compared to priming with the control $(\mathrm{df}=21$, $\mathrm{t}=-2.43, \mathrm{p}=0.026$; Figure $2 \mathrm{a}$ ). The lytic activity and PO activity did not differ between the two treatments (Lytic: $\mathrm{df}=20, \mathrm{U}=54.50, \mathrm{p}=0.679$; PO: $\mathrm{df}=21, \mathrm{t}=0.17$, $\mathrm{p}=0.987$; Figure $2 \mathrm{~b} \& \mathrm{c}$ ).

\section{Discussion}

Here we show that a previous oral exposure to $S$. marcescens protects $P$. plantaginis larvae from an otherwise lethal septic infection with the same pathogen. As a response to the priming with $S$. marcescens the moth larvae also

\section{Table 1 Pairwise differences in larval mortality between} the priming-injection treatments

\begin{tabular}{|c|c|c|c|c|c|c|}
\hline \multirow[t]{2}{*}{ Priming-injection } & \multicolumn{2}{|c|}{ Serratia-control } & \multicolumn{2}{|c|}{ control-Serratia } & \multicolumn{2}{|c|}{ control-control } \\
\hline & $x^{2}$ & Sig. & $x^{2}$ & Sig. & $x^{2}$ & Sig. \\
\hline Serratia-Serratia & 12.641 & $<0.001$ & 64.92 & $<0.001$ & 19.72 & $<0.001$ \\
\hline Serratia-control & & & 115.38 & $<0.001$ & 1.07 & 0.300 \\
\hline control-Serratia & & & & & 130.57 & $<0.001$ \\
\hline
\end{tabular}

The larvae were primed orally with either a non-infective dose of pathogenic Serratia marcescens or a non-pathogenic control bacterium Escherichia coli, and five days later injected with the same or different bacteria.

Statistically significant pairwise differences are bolded. 


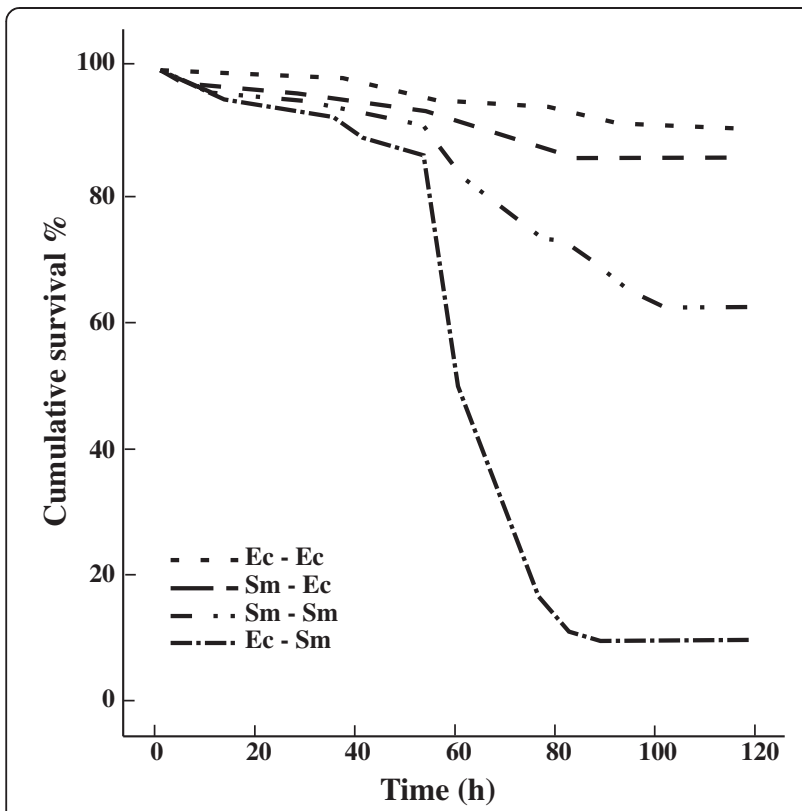

Figure 1 Larval survival after septic injury. The four survival curves present different priming-injection groups, where the first term is bacteria used in the priming, and second term bacteria used in septic infection $120 \mathrm{~h}$ later. Ec stands for the control bacterium, E. coli, and Sm for S. marcescens. Treatments from the least to the most virulent combination: $\mathrm{Ec}-\mathrm{Ec}<\mathrm{Sm}-\mathrm{Ec}<\mathrm{Sm}-\mathrm{Sm}<\mathrm{Ec}-\mathrm{Sm}$

showed elevated levels of reactive oxygen species in their haemolymph five days post-treatment, offering a potential explanation for the protection. The elevated ROS levels were measured prior to the secondary immune challenge, which suggests that the mechanism for the prophylaxis could be due to immunological loitering rather than enhanced capacity to re-upregulate immune defences. This is in agreement with earlier studies, which show that different immune molecules can remain in the hemolymph days or even weeks after the immune challenge [22]. It might be that this simple kind of acquired resistance is more prevalent in short lived insects than generally acknowledged, and serves as a natural "vaccination" if pathogens are first detected in sub-lethal doses. The results do not rule out the possibility that insects could, after down regulation, reactivate a stronger immune reaction against a pathogen they have already encountered, which would be functionally more analogous to immunological memory than a simple persistent immune response. It is, for example, possible that immunological loitering and more "memory-like" functions act in concert to fight recurring infections $[1,4]$. It could also be that some other molecules, such as antimicrobial peptides Cecropins or Gloverin, that we did not measure are up regulated with ROS and that the persistent protection is not solely due to oxidative defence [28].

S. marcescens is very common in the environment, e.g. soil, water and plants, and is often isolated from many insect species across various taxa [34,35]. Thus, it is likely that $P$. plantaginis falls within S. marcescens' natural host range and real life encounters via contaminated host plants are possible in the wild. It has been shown that a septic infection with Serratia in insects can occur in the wild via, for example, an ovipositor of Hymenopteran parasite [36], a nematode vector [37], or a spontaneous gut rupture [34]. It would be of great benefit for the host
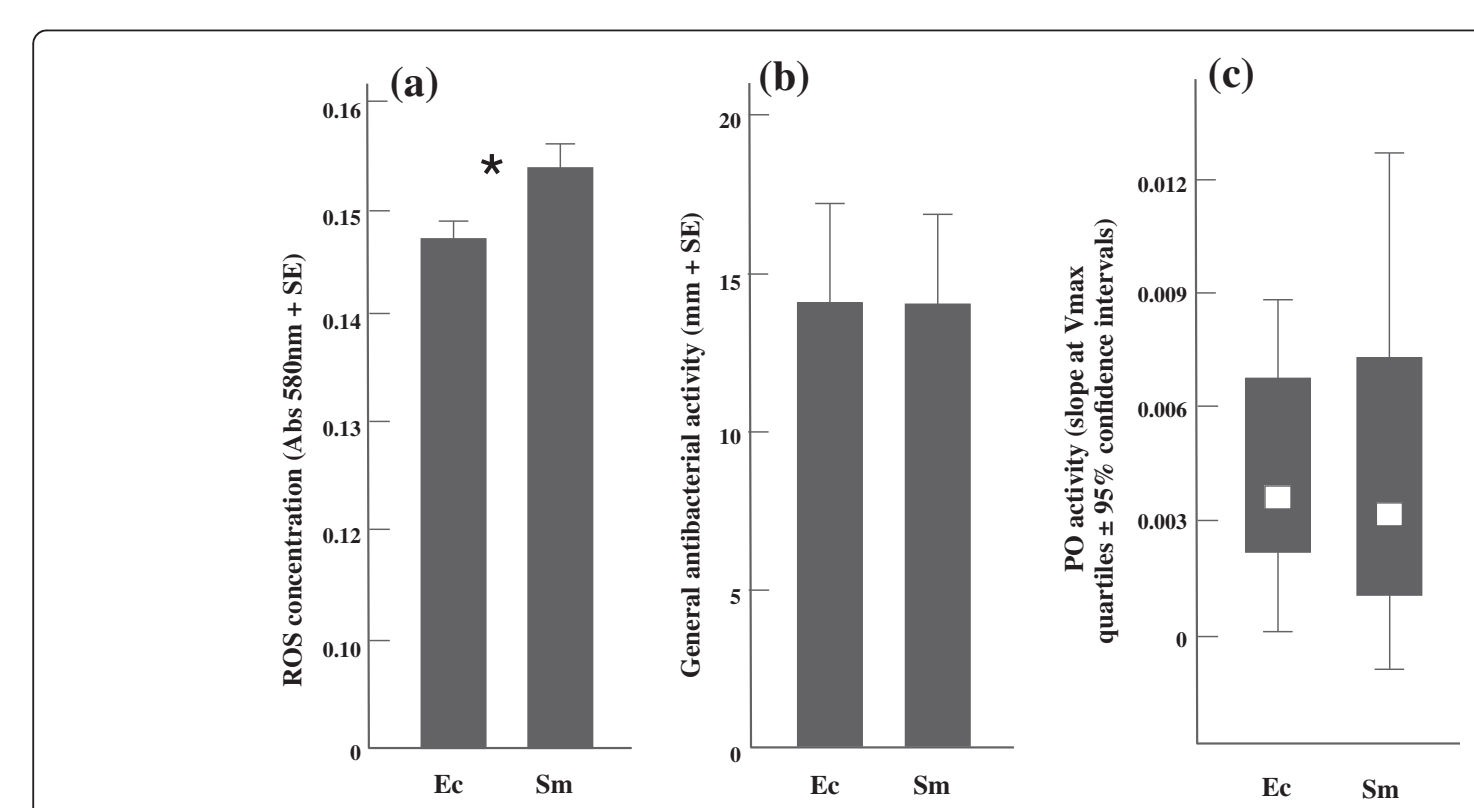

Figure 2 The immune assays from differently primed larvae $120 \mathrm{~h}$ after the initial exposure. Ec stands for the control bacterium, E. coli, and Sm for S. marcescens. Asterisk $\left(^{*}\right)$ indicates a significant $(<0.05)$ difference between the oral priming treatments. The amount of ROS in the haemolymph (a), the lytic activity (b) and the PO activity (c). 
to be prepared in advance for such a sudden and intensive immune insult.

We detected higher levels of ROS from the hemolymph of $S$. marcescens-exposed larvae compared to the control group fed with the non-pathogenic E. coli. This is a wellknown anti-microbial defence mechanism in insects [25], and could have mediated the higher survival when the larvae were infected again with the pathogen. However, the ROS defence alone might not be sufficient to control large doses of $S$. marcescens in septic injury. This is because the bacterium is known to be fairly tolerant against oxidative stress via production of cellular catalases [38]. In addition, ROS are usually thought to control gut microbiota, and might not directly protect against injected pathogens $[28,39]$. The increased levels of ROS in our study, however, were measured straight from the haemolymph sample. Thus, higher levels of ROS may initially help keep the septic infection under control until other aspects of immunity can diminish it; and/or ROS mediates the regulation of other antimicrobials, such as Diptericin in Drosophila [40].

Interestingly, we did not find correlations between the measured immune traits although several previous studies suggest negative genotypic and phenotypic correlations between different defences [41-43]. For example, encapsulation and lytic activity, which might be targeted against different invaders, have been shown to correlate negatively in a field cricket, Gryllus bimaculatus [44]. Two major immunocompetence measures, PO and lytic activity, have been criticized by claiming that these indicators do not predict resistance against a challenge with natural parasites $[45,46]$. Our findings show ROS being upregulated in the pathogen challenged group, whereas PO and lytic activity show no change. However, the upregulation of different immune pathways are most likely pathogen and host specific. Indeed, it has been shown that Daphnia magna with higher induced PO levels are more resistant to their parasite Pasteuria ramosa [24]. Our observation of the lack of negative relationships within the immune system traits does not mean that the ROS response would be trade-off free. The major cost of resistance, in this case, could result from the non-specific nature of ROS molecules that are well known to cause selfharm and early senescence $[30,40,47]$. This could mean that prolonged exposure to the free radicals in the haemolymph requires additional resources to deal with potential tissue damage. Also, pathogen induced persistent immune reactions could have adverse effects on the native gut flora, indirectly contributing to fitness consequences [48].

Given the obvious costs, hosts should avoid unnecessary upregulation of immune responses. Imd-pathway mediated immune defence is often thought to be activated by the presence of peptidoglycan fragments from any gramnegative bacteria [25]. Nehme et al. [27] also proposed this to be the case between Drosophila and $S$. marcescens in septic infection. However, even the highly virulent $S$. marcescens db11-strain did not elicit an immune response via the oral route in that particular system. The defence observed in this paper must have been triggered by a more specific mechanism than a general response to the presence of gram-negative bacteria in the gut because priming with the control bacterium failed to confer the protection. Both bacteria exhibit DAP-type peptidoglycan in their cell wall, which has been shown to activate the Imd-pathway, in contrast to Lys-type found in gram-positives and the Bacillus group [49]. It has been suggested that in Drosophila larvae, haemocytes in the gut can signal pathogen presence to the fat body, via cytokines or by releasing ingested cell wall fragments $[50,51]$. It is thus possible that $P$. plantaginis haemocytes can recognize potentially harmful $S$. marcescens and ignore benign bacteria. Also, bacterial immune elicitors (e.g. peptidoglycan or lipopolysaccharides) are known to bind to a storage and transport protein vitellogenin in fish $[52,53]$. It is also a very abundant protein in the insect hemolymph [54] and, interestingly, has antioxidative capabilities protecting organisms against free radical stress [55]. In another lepidopteran, Manduca sexta, direct inoculation of $E$. coli in the haemocoel has been shown to offer resistance against Photorhabdus luminescens via upregulation of pattern recognition proteins [56]. The seemingly contradictory results with our experiment probably stem from the priming method: if introduced orally, E. coli most likely does not penetrate the gut epithelium, nor it is beneficial for the host to actively present antigens from a non-pathogenic bacteria to the fat body or haemolymph [50,51]. In our study, S. marcescens, but not E. coli, offered the protection and elicited the systemic ROS response in the haemocoel when detected in the gut. The different result with septic first exposure thus provides further support for the intestinal recognition of pathogenic and non-pathogenic bacteria and for the immune systems ability to mount a corresponding systemic defence. Another alternative explanation is that our non-pathogenic control bacterium appears in the gut in quantities that do not exceed the detection threshold of the recognition proteins, compared to $S$. marcescens that might still proliferate in the gut even when being avirulent [27]. Regardless of the mechanism, a harmless encounter with a pathogen via gut transfers into a systemic immune reaction that protects $P$. plantaginis larvae when substantial amount of the same pathogen is introduced straight into haemocoel later in life.

\section{Conclusions}

A lepidopteran species, although having a relatively short life span, remains protected against a previously encountered pathogen, possibly because of persistent 
immune responses involving free radicals. The findings evoke interesting questions on the evolutionary and epidemiological consequences that priming might have in insect populations, through increased resistance, and on the other hand, through increased costs due to oxidative stress. Although the ecological and evolutionary effects of priming are very hard to study at the population level in the wild, modelling suggests that it has evident consequences on both pathogen (disease prevalence) and host (demographic structure) population dynamics, as well as on the stability of host-parasite systems $[57,58]$.

\section{Material and methods}

\section{Study species}

P. plantaginis, the wood tiger moth, is a day active moth distributed over the northern hemisphere. It has been extensively studied for its warning coloration [59-61]. Also, a few studies describe moth immunocompetence, and interaction between larvae and $S$. marcescens. For example, larval diet has been shown to have a substantial effect on the level of immune defence [62-64]. Larvae used in this experiment were obtained from a population originating from wild individuals caught in southern Finland and kept for three generations in the laboratory (see methods for rearing in [61]).

S. marcescens is a cosmopolite opportunistic pathogen that is commonly found in water and soil. It causes nosocomial infections in humans and has been isolated from various insect species $[34,35,65]$. The strain used in the experiment was obtained from American Type Culture Collection (ATCC\# 13880). Laboratory adapted E. coli $\mathrm{K}-12$ was used as the non-pathogenic control strain. The bacteria were maintained in standard LB-medium (10 g tryptone, $5 \mathrm{~g}$ yeast extract, $10 \mathrm{~g} \mathrm{NaCl}$ in $1 \mathrm{~L}$ of $\mathrm{dH}_{2} \mathrm{O}$ ).

\section{Priming and injection}

416 three-week-old moth larvae were weighed, after which they were randomised to the two primary exposure treatments (S. marcescens, $\mathrm{N}=207$ and $E$. coli, $\mathrm{N}=209)$. E. coli was used as a control treatment instead of a completely naïve group because we wanted to see how the sheer presence of gram-negative bacteria in the diet would compare to the actual pathogen. It has been shown previously that in spite of being non-pathogenic, the presence of $E$. coli may induce a general immune reaction in insects e.g. $[41,66]$. The larvae were placed individually on Petri dishes and reared at $21^{\circ} \mathrm{C}$ under a 15 hour light: 9 hour dark cycle. Larval weight did not differ between treatments $(\mathrm{df}=414, \mathrm{t}=-0.6, \mathrm{p}=0.55)$. Larvae were first fed with their natural diet, dandelion (Taraxacum $s p$ ), after which it was supplemented with the priming cultures. The bacterial mass was grown overnight on LB-agar plates in $31^{\circ} \mathrm{C}$, scraped off with sterile loops and mixed to liquid LB. To standardise the amount of cells the mass was diluted until 0.50 optical density (OD) at $600 \mathrm{~nm}$ was reached. These dilutions were then added to the larval diet by pipetting a 200- $\mu$ l droplet (approximately $6 \times$ $10^{7}$ cells) of the priming solution to each dandelion leaf surface. After $48 \mathrm{~h}$, majority of the larvae had consumed all the contaminated food and they were given normal diet again. $120 \mathrm{~h}$ after the primary priming exposure larvae were infected by injecting $2 \mu \mathrm{l}$ (OD 0.16, $90000 \mathrm{~S}$. marcescens and 110000 E. coli cells) of bacteria (the previously encountered pathogen, or the control bacterium) directly into the body cavity. The injection was given behind the fifth proleg with a $10 \mu \mathrm{l}$ Hamilton syringe. The larvae were kept under constant conditions with ad libitum food and survival was recorded every three hours. We took haemolymph samples from 15 random larvae (not included in the survival analysis) per priming treatment before the injection.

\section{Immune assays}

$\mathrm{PO}$ and ROS activities were estimated from samples containing $10 \mu \mathrm{l}$ of larval haemolymph diluted in $30 \mu \mathrm{l}$ ice-cold potassium phosphate buffer which was then frozen at $-80^{\circ} \mathrm{C}$. For measurements, the samples were thawed and centrifuged $(9000 \mathrm{~g})$ at $4^{\circ} \mathrm{C}$ for 10 minutes to obtain the clear supernatant. For PO, $25 \mu \mathrm{l}$ of supernatant was added to $200 \mu \mathrm{l}$ of $3 \mathrm{mM}$ L-Dopa (Sigma, \#333786). Kinetic activity of the enzyme was measured at $30^{\circ} \mathrm{C}$, $490 \mathrm{~nm}$ for 90 minutes (1 minute intervals) with Victor X4 2030 plate reader (Perkin Elmer, Waltham, MA, US). The slope of the absorbance curve from 10-80 minutes was used in the analyses [41].

Pierce PeroXOquant ${ }^{\text {tm }}$ quantitative peroxide assay kit (Thermo Scientific, Waltham, MA, US \#23280) was used to estimate the amount of ROS in the haemolymph: $5 \mu \mathrm{l}$ of the supernatant was mixed with $90 \mu \mathrm{l}$ of the manufacturers working solution. Eight dilutions (ranging from 1 to $1000 \mu \mathrm{M})$ of $\mathrm{H}_{2} \mathrm{O}_{2}$ were used as standards. The mix was left to stabilize at room temperature for $25 \mathrm{~min}$ after which absorbance was read with a Bioscreen ${ }^{\text {tux }}$ spectrophotometer (Growth Curves Ltd., Helsinki, Finland) at $580 \mathrm{~nm}$.

Lytic activity was assessed straight from the haemolymph samples by pipetting $5 \mu \mathrm{l}$ of fresh haemolymph into a $2.2 \mathrm{~mm}$ diameter wells punctured on Micrococcus (ATCC \#4698) agar plate, incubated over night in $31^{\circ} \mathrm{C}$ and then photographed. 7 serial dilutions $(0.031-2.0 \mathrm{mg} / \mathrm{mL})$ of lysozyme (Sigma, \#L7651) were used as standards. Lytic activity was measured from the photo as the diameter of a degradation halo around the well [41].

\section{Statistical analyses}

Larval survival was first analysed using Cox-regression with priming, injection, and their interaction in the model. The four priming-injection groups (Serratia-control, control-control, Serratia-Serratia and control-Serratia) were 
then compared with pairwise Kaplan-Meyer survival analysis. PO activity and ROS were analysed with a t-test. Mann-Whitney U-test was used for lytic activity because of non-normal distribution. All analyses were performed with SPSS statistics 21.0.

\section{Competing interests}

The authors declare that they have no competing interests.

\section{Authors' contributions}

$L M, J M, M K$, and DF designed the experiment and carried out the experimental work. LM and DF analyzed the data. LM, JM, and DF wrote the manuscript. All authors read and approved the final manuscript.

\section{Acknowledgements}

The authors thank Kaisa Suisto \& Jimi Kirvesoja for their help with the experiment, Tarmo Ketola, Kalevi Viipale and two anonymous reviewers for comments, and Swanne Gordon \& Samuel Waldron for improving the language. Finnish Cultural Foundation (LM), Vanamo Foundation (MK), The Academy of Finland (project 1268, JM), and the Finnish Centre of Excellence in Biological Interactions (DF, MK, JM and LM) funded the study.

\section{Author details}

'Centre of Excellence in Biological Interactions, Department of Biological and Environmental Science, University of Jyväskylä, P.O. Box 35, Jyväskylä Fl-40014, Finland. ${ }^{2}$ Centre of Excellence in Biological Interactions, Department of Biosciences, University of Helsinki, P.O. Box 65, Helsinki Fl-00014, Finland.

Received: 13 February 2014 Accepted: 3 March 2014

Published: 7 March 2014

\section{References}

1. Kurtz J: Specific memory within innate immune systems. Trends Immunol 2005, 26:186-192.

2. Moret $Y$, Siva-Jothy MT: Adaptive innate immunity? Responsive-mode prophylaxis in the mealworm beetle, Tenebrio molitor. Proc R Soc B 2003, 270:2475-2480.

3. Little TJ, Kraaijeveld AR: Ecological and evolutionary implications of immunological priming in invertebrates. Trends Ecol Evol 2004, 19:58-60.

4. Sadd BM, Schmid-Hempel P: Insect immunity shows specificity in protection upon secondary pathogen exposure. Curr Biol 2006, 16:1206-1210.

5. Roth O, Sadd BM, Schmid-Hempel P, Kurtz J: Strain-specific priming of resistance in the red flour beetle, Tribolium castaneum. Proc R SOC B 2009, 276:145-151.

6. Tidbury $H J$, Pedersen $A B$, Boots $M$ : Within and transgenerational immune priming in an insect to a DNAvirus. Proc R Soc B 2011, 278:871-876.

7. Pham LN, Dionne MS, Shirasu-Hiza M, Schneider DS: A specific primed immune response in drosophila is dependent on phagocytes. PLoS Pathog 2007, 3:e26.

8. Criscitiello MF, de Figueiredo P: Fifty shades of immune defense. PLOS Pathog 2013, 9:e1003110.

9. Sheldon BC, Verhulst S: Ecological immunology: costly parasite defences and trade-offs in evolutionary ecology. Trends Ecol Evol 1996, 11:317-321

10. Kraaijeveld AR, Godfray HCJ: Tradeoff between parasitoid resistance and larval competitive ability in Drosophila melanogaster. Nature 1997, 389:278-280.

11. Ardia DR, Gantz JE, Schneider BC, Strebel S: Costs of immunity in insects: an induced immune response increases metabolic rate and decreases antimicrobial activity. Func Ecol 2012, 26:732-739.

12. Armitage SA, Thompson JJ, Rolff J, Siva-Jothy MT: Examining costs of induced and constitutive immune investment in Tenebrio molitor. J Evol Biol 2003, 16:1038-1044.

13. Zuk M, Stoehr AM: Immune defense and host life history. Am Nat 2002, 160:S9-S22.

14. Schmid-Hempel P, Ebert D: On the evolutionary ecology of specific immune defence. Trends Ecol Evol 2003, 18:27-32.

15. McTaggart SJ, Wilson PJ, Little TJ: Daphnia magna shows reduced infection upon secondary exposure to a pathogen. Biol Lett 2012, 8:972-975.
16. Wilson K, Thomas MB, Blanford S, Doggett M, Simpson SJ, Moore SL: Coping with crowds: density-dependent disease resistance in desert locusts. Proc Natl Acad Sci U S A 2002, 99:5471-5475.

17. Jarosz J: Induction kinetics of immune antibacterial proteins in pupae of Galleria mellonella and Pieris brassicae. Comp Biochem Physiol 1993, 106B:415-421.

18. Azambuja PD, Freitas CC, Garcia ES: Evidence and partial characterization of an inducible antibacterial factor in the haemolymph of Rhodnius prolixus. J Insect Physiol 1986, 32:807-812.

19. Bulet $\mathrm{P}$, Cociancich S, Dimarcq J-L, Lambert J, Reichhart J-M, Hoffmann D, Hetru C, Hoffmann JA: Isolation from a Coleopteran insect of a novel inducible antibacterial peptide and of new members of the insect defensin family. J Biol Chem 1991, 266:24520-24525.

20. Bulet $P$, Cociancich $S$, Reuland M, Sauber F, Bischoff R, Hegy G, Van Dorsselaer A, Hetru C, Hoffmann JA: A novel insect defensin mediates the inducible antibacterial activity in larvae of the dragonfly Aeschna cyanea (Paleoptera, Odonoata). Eur J Biochem 1992, 209:977-984.

21. Korner $P$, Schmid-Hempel $P$ : In vivo dynamics of an immune response in the bumble bee Bombus terrestris. J Invertebr Pathol 2004, 87:59-66.

22. Haine ER, Pollit LC, Moret Y, Siva-Jothy MT, Rolff J: Temporal patterns in immune responses to a range of microbial insults (Tenebrio molitor). J Insect Physiol 2008, 54:1090-1097.

23. Faye I, Pye A, Rasmuson T, Boman HG, Boman IA: Insect immunity II. Simultaneous induction of antibacterial activity and selective synthesis of some hemolymph proteins in diapausing pupae of Hyalophora cecropia and Samia cynthis. Infect Immun 1975, 12:1426-1438.

24. Pauwels K, De Meester L, Decaestecker E, Stoks R: Phenoloxidase but not lytic activity reflects resistance against Pasteuria ramosa in Daphnia magna. Biol Lett 2011, 7:156-159.

25. Broderick NA, Welchman DP, Lemaitre B: Recognition and response to microbial infection in Drosophila. In Insect Infection and Immunity - Evolution, Ecology, and Mechanisms. Edited by Rolff J, Reynolds SE. New York, USA: Oxford University Press; 2009:13-33.

26. Rämet M, Manfruelli P, Pearson A, Mathey-Prevot B, Ezekowitz RAB: Functional genomic analysis of phagocytosis and identification of a Drosophila receptor for E. coli. Nature 2002, 416:644-648.

27. Nehme N, Liégeois S, Kele B, Giammarinaro P, Pradel E, Hoffmann J, Ewbank $\mathrm{J}$, Ferrandon D: A model of bacterial intestinal infections in Drosophila melanogaster. PLoS Pathog 2007, 3:1694-1709.

28. Vallet-Gely I, Lemaitre B, Boccard F: Bacterial strategies to overcome insect defences. Nat Rev Microbiol 2008, 6:302-313.

29. Dowling DK, Simmons LW: Reactive oxygen species as universal constraints in life-history evolution. Proc R SOC B 2009, 276:1737-1745.

30. Sadd BM, Siva-Jothy MT: Self-harm caused by an insect's innate immunity. Proc R Soc B 2006, 273:2571-2574.

31. Roth $\mathrm{O}$, Kurtz J: Phagocytosis mediates specificity in the immune defence of an invertebrate, the woodlouse Porcellio scaber (Crustacea: Isopoda). Dev Comp Immunol 2009, 33:1151-1155.

32. Wang J, Wang L, Yang C, Jiang Q, Zhang H, Yue F, Huang M, Sun Z, Song $L$ : The response of mRNA expression upon secondary challenge with Vibrio anguillarum suggests the involvement of C-lectins in the immune priming of scallop Chlamys farreri. Dev Comp Immunol 2013, 40:142-147.

33. Sadd BM, Kleinlogel Y, Schmid-Hempel R, Schmid-Hempel P: Trans-generational immune priming in a social insect. Biol Lett 2005, 1:386-388.

34. Grimont PAD, Grimont F: The genus Serratia. Annu Rev Microbiol 1978, 32:221-248

35. Flyg C, Kenne K, Boman HG: Insect pathogenic properties of Serratia marcescens: phage-resistant mutants with a decreased resistance to Cecropia immunity and a decreased virulence to Drosophila. J Gen Microbiol 1980, 120:173-181.

36. Bucher GE: Transmission of bacterial pathogens by the ovipositor of a hymenopterous parasite. J Insect Pathol 1963, 5:277-283.

37. Petersen LM, Tisa LS: Influence of temperature on the physiology and virulence of the insect pathogen Serratia sp. Strain SCBI. Appl Environ Microbiol 2012, 78:8840-8844

38. Campbell JE, Dimmick RL: Effect of $3 \%$ hydrogen peroxide on the viability of Serratia marcescens. J Bacteriol 1966, 91:925-929.

39. Diaz-Albiter H, Sant'Anna MRV, Genta FA, Dillon RJ: Reactive oxygen species-mediated immunity against Leishmania Mexicana and Serratia 
marcescens in the Phlebotomine Sand fly Lutzomyia longipalpis. J Biol Chem 2012, 287:23995-24003.

40. Wu SC, Liao CW, Pan RL, Juang JL: Infection-induced intestinal oxidative stress triggers organ-to-organ immunological communication in Drosophila. Cell Host Microbe 2012, 11:410-417.

41. Freitak D, Wheat CW, Heckel DG, Vogel H: Immune system responses and fitness costs associated with consumption of bacteria in larvae of Trichoplusia ni. BMC Biol 2007, 5:56

42. Cotter SC, Kruuk LEB, Wilson K: Costs of resistance: genetic correlations and potential trade-offs in an insect immune system. J Evol Biol 2004, 17:421-429.

43. Moret $Y$, Schmid-Hempel P: Immune defence in bumble-bee offspring. Nature 2001, 414:506-506.

44. Rantala MJ, Kortet R: Courtship song and immune function in the field cricket Gryllus bimaculatus. Biol J Linn Soc 2003, 79:503-510.

45. Adamo SA: Estimating disease resistance in insects: phenoloxidase and lysozyme-like activity and disease resistance in the cricket Gryllus texensis. J Insect Physiol 2004, 50:209-216.

46. Mucklow PT, Vizoso DB, Jensen KH, Refardt D, Ebert D: Variation in phenoloxidase activity and its relation to parasite resistance within and between populations of Daphnia magna. Proc R Soc B 2004, 271:1175-1183.

47. Sohal RS, Weindruch R: Oxidative stress, caloric restriction, and aging. Science 1996, 273:59-63.

48. Dillon RJ, Dillon VM: The gut bacteria of insects: nonpathogenic interactions. Annu Rev Entomol 2004, 49:71-92.

49. Steiner H: Peptidoglycan recognition proteins: on and off switches for innate immunity. Immunol Rev 2004, 198:83-96.

50. Basset A, Khush RS, Braun A, Gardan L, Boccard F, Hoffmann JA, Lemaitre B: The phytopathogenic bacteria Erwinia carotovora infects Drosophila and activates an immune response. Proc Natl Acad Sci U S A 2000, 97:3376-3381.

51. Brennan CA, Delaney JR, Schneider DS, Anderson KV: Psidin is required in Drosophila blood cells for both phagocytic degradation and immune activation of the fat body. Curr Biol 2007, 17:67-72.

52. Tong Z, Li L, Pawar R, Zhang S: Vitellogenin is an acute phase protein with bacterial-binding and inhibiting activities. Immunobiology 2010, 215:898-902.

53. Zhang S, Wang S, Li H, Li L: Vitellogenin, a multivalent sensor and an antimicrobial effector. Int J Biochem Cell Biol 2011, 43:303-305.

54. Freitak D, Heckel DG, Vogel H: Dietary-dependent trans-generational immune priming in an insect herbivore. Proc $R$ Soc $B 2009$, 276:2617-2624

55. Havukainen H, Munch D, Baumann A, Zhong S, Halskau Ø, Krogsgaard M, Amdam GV: Vitellogenin recognizes cell damage through membrane binding and shields living cells from reactive oxygen species. J Bio/ Chem 2013, 288:28369-28381.

56. Eleftherianos I, Marokhazi J, Millichap PJ, Hodgkinson AJ, Sriboonlert A, Ffrench-Constant RH, Reynolds SE: Prior infection of Manduca sexta with non-pathogenic Escherichia coli elicits immunity to pathogenic Photorhabdus luminescens: roles of immune-related proteins shown by RNA interference. Insect Biochem Mol Biol 2006, 36:517-525.

57. Tate AT, Rudolf VHW: Impacts of life stage specific immune priming on invertebrate disease dynamics. Oikos 2012, 121:1083-1092.

58. Tidbury HJ, Best A, Boots M: The epidemiological consequences of immune priming. Proc R SOC B 2012, 279:4505-4512.

59. Ojala K, Lindström L, Mappes J: Life-history constraints and warning signal expression in an Arctiid moth. Func Ecol 2007, 21:1162-1167.

60. Lindstedt C, Lindström L, Mappes J: Hairiness and warning colours as components of antipredator defence: additive or interactive benefits? Anim Behav 2008, 75:1703-1713.

61. Lindstedt $C$, Lindström L, Mappes J: Thermoregulation constrains effective warning signal expression. Evolution 2009, 63:469-478.

62. Friman V-P, Lindstedt C, Hiltunen T, Laakso J, Mappes J: Predation on multiple trophic levels shapes the evolution of pathogen virulence. PLoS One 2009, 4:e6761.
63. Ojala K, Julkunen-Tiitto R, Lindström L, Mappes J: Diet affects the encapsulation ability of an Arctiid moth Parasemia planataginis. Evol Ecol Res 2005, 7:1153-1170.

64. Zhang J, Friman V-P, Laakso J, Mappes J: Interactive effects between diet and genotypes of host and pathogen define the severity of infection. Ecol Evol 2012, 2:2347-2356.

65. Mahlen SD: Serratia infections: from military experiments to current practice. Clin Microbiol Rev 2011, 24:755-791.

doi:10.1186/1742-9994-11-23

Cite this article as: Mikonranta et al:: Insect immunity: oral exposure to a bacterial pathogen elicits free radical response and protects from a recurring infection. Frontiers in Zoology 2014 11:23.

\section{Submit your next manuscript to BioMed Central and take full advantage of:}

- Convenient online submission

- Thorough peer review

- No space constraints or color figure charges

- Immediate publication on acceptance

- Inclusion in PubMed, CAS, Scopus and Google Scholar

- Research which is freely available for redistribution

Submit your manuscript at www.biomedcentral.com/submit
C) BioMed Central 